may not appeal to the reader of literary works.

Have the 400,000 hours of work which have gone into making this set of the works of seventy-six authors been worth the effort? Why such hard readings? It may be replied that no easy way of thinking has yet been devised. Anyone who has studied worth while authors has found that certain themes run through them. These themes recur because they deal with the hopes, wishes, joys, anxieties, and pains of man. Man changes, but he is essentially man, as he was thirty centuries ago. $\mathrm{He}$ is inescapably concerned with questions about himselff, his surroundings, God, freedom. These universal questions are again and again appearing and will continue to appear. The twentieth century has the old problems of wars, persecution, and enslavement. The great writings are considered great because of their beauty, insight, or profound discussion of man's problems. The editors of the Syntopicon did not make an arbitrary list. They included many of the ideas which man has had. There may and should be differences of opinion concerning the inclusion of certain of them. By placing these books in a set and providing them with an index, the editors have made possible the tracing of important ideas.

It is true that the great writers often failed in their day. They did not always stop wars or save civilizations. They warned their countrymen, but their voices were not heard. In retrospect we should be able to interpret what they said. Some were, from our point of view, reactionary or false. For this very reason they may be worth our attention. Since the great writers often disagree, this set cannot be said to be a canonization of them. Many of them are ancient, but more than one-half of them lived between 1500 and 1900 A.D. If anyone would understand the American government, let him read Locke as well as "The Declaration of Independence," "The Federalist," and "The Constitution of the United States." $\mathrm{He}$ will derive benefit from contemporary books, but he will be less easily indoctrinated if he reads and thinks about these basic works.

The Great Books of the Western World are only some of the books that are worth reading. They should have their chance along with others. They will be used as teachers and librarians let people know that they exist.

It is to be hoped that some way of circulating them may be found. There is nothing final about them, for as the editors have told us, each generation should evaluate its tradition in the light of its own needs. The test applied to other works of man should be applied to this. Whether it is a great and useful work, only time will tell.-Margaret Pierson, Indiana State Library.

\section{Variations on an}

Index Theme
When is an index a syntopicon?

According to the editor a syntopicon is "a collection of the topics which are the main theme of the conversation to be found in the books .... its primary purpose-to serve as a guide to the reading of Great Books of the Western World. . . .

"The specific type of inquiry which the Syntopicon is able to satisfy . . . can be formulated by the question, What do the great books have to say on this subject?"

There is much more explanation in the 80page essay about the principles and methods of syntopical construction, which is appendix II of the Syntopicon's second volume. But it all adds up to the fact that a syntopicon is another variation in the numerous attempts to improve the index as a locator of information buried in sets of books and periodicals or in individual volumes of collections.

Basically, the Syntopicon consists of 163,000 entries. This number, alone, makes it a major index. It compares in size with the larger indexes to encyclopedias and other basic reference books. The same publisher's Encyclopedia Britannica with some 500,000 index entries, as well as the Americana and Collier's Encyclopedias, include larger indexes. So do such separate indexing ventures as the Essay and General Literature Index and any one of several other Wilson indexes. But the Syntopicon is in this class of indexing and as such deserves close scrutiny by librarianship as a possible innovation in the art and technique of indexing.

The first difference to note is the unique application of three basic indexing arrangements - alphabetic, classified, chronologic. There are 102 "ideas" (major heads in index parlance) arranged alphabetically from "Angel" through "World." Selection of these heads in preference to others is based on no 
library list of subject headings and is admittedly subjective.

A second difference to note is that each of these major heads is separated by long essays from the classified headings, the chronologic sub-headings, and the sequential references. Something comparable can be found in reference literature in the case of volume 19 of the $W$ orld Book Encyclopedia. But the Syntopicon differs not only because of the intervening essays but because of the chronologic rather than classified or alphabetic sequence of sub-heads.

A third difference to note is the inclusion of two features, usually found elsewhere in reference books, as part of the index. One of these is the Bibliography of Additional Readings, which is arranged alphabetically by author, with no analysis by the 102 ideas or subheads. The other feature is the Inventory of Terms, a sort of alphabetical finding list for the headings used.

Overwhelmingly the impression left on this reviewer is that the Syntopicon is unnecessarily complex. At times one feels as though the indexing staff responsible for the $S y n$ topicon is about to come to grips with some fundamental problems that have frustrated indexers for years. But at other times and especially while reading the 80-page appendix on "Principles and Methods of Syntopical Construction" one has the uncomfortable feeling that the author is one of those intelligent readers who has spent his reading life either taking for granted or minimizing the importance of indexes until this moment when called upon to assume responsibility for constructing one, and then, suddenly aware that indexing is a fundamental, but still not fully initiated in the art, sets out to philosophize about elementaries explained in the first few days of library school.

The inadequacy of the Syntopicon as an index seems, to this reviewer, to stem from a faulty concept of a reference book. "The Syntopicon does not contain the answers, but only a guide to where the answers can be found in the pages of the great books." (Preface XXII). According to the editor, "This fact distinguishes the Syntopicon from all other familiar reference books, which contain within themselves the answers to the questions on which they are consulted." Of course, this isn't quite so. The Essay and
General Literature Index, for example, a "familiar reference book," shares the Syntopicon's distinction, as do numerous other bibliographies and indexes. As a matter of fact, the Syntopicon as well as these other bibliographic reference tools, often do contain within themselves the answers to some of the questions for which they are consulted.

From the standpoint of the readers' adviser in the public library the Syntopicon will not be an easy tool to use. For quick reference the quotation book will be better for a few words on almost any idea in the $S y n$ topicon. So will the good encyclopedia index, the Essay and General Literature Index, the new Granger's Index to Poetry, and volume 50 of the Harvard Classics.

The great contribution of the Syntopicon will probably be in the field of public relations. It may, through all the dramatic attention it has received in the press, serve to bring some of the long overdue appreciation due the much underrated art of indexing.-Louis Shores, Florida State University, Tallahassee.

\section{With the publication in Rolumes of the Great Reference Tool Books of the Western World, the Hutchins-} Adler-Barr group has taken another step in the direction of promoting the study of the books they consider fundamental to an understanding of western thought. This set, much like other similar ventures in the selection and publication of great works, consists of many books that are standard works to be found in most library collections. So the librarian may very well hesitate in acquiring it for the library. But there has been added to this collection a unique topical index, called the Syntopicon, which gives it an importance not previously achieved by any similar set of volumes. It makes easily accessible the contents of the works included in a way they have not been made accessible before, either through bibliographies, dictionaries, concordances, encyclopedias, or indexes to individual works. The thoroughness with which the Syntopicon performs its task and the manner in which it does it, make it an outstanding intellectual achievement and an important new reference tool for the scholar, the student, and the reference librarian-this, regardless of the extent to which one may agree with the 